Research Article

\title{
Research on Structural Design of an Isolated High-Rise Building with Enlarged Base and Multiple Tower Layer in High-Intensity Area
}

\author{
Haotian Zhang $\mathbb{D}^{1},{ }^{1}$ Fuju Li $\mathbb{D D}^{1},{ }^{1}$ Ji Tai $\mathbb{D}^{2},{ }^{2}$ and Jun Zhou $\mathbb{D}^{2}$ \\ ${ }^{1}$ Changchun University of Architecture and Civil Engineering, Changchun 130021, China \\ ${ }^{2}$ Jilin Construction Engineering Group Co., Ltd, Changchun 130041, China
}

Correspondence should be addressed to Haotian Zhang; showutheway@126.com

Received 1 November 2020; Revised 18 March 2021; Accepted 2 April 2021; Published 16 April 2021

Academic Editor: Krzysztof Puszynski

Copyright (C) 2021 Haotian Zhang et al. This is an open access article distributed under the Creative Commons Attribution License, which permits unrestricted use, distribution, and reproduction in any medium, provided the original work is properly cited.

In the high intensity areas, the application of interlayer spacing technology can achieve the unity of quality and seismic performance of high-rise buildings with enlarged base and multiple tower layers. Through the comparison and analysis of the structural schemes of an enlarged base multiple tower-layer high-rise building, the ultimate seismic isolation scheme was adopted, and its seismic response and seismic performance were analyzed and studied. The results show that the overall seismic isolation effect of the story isolation technique is good, which can greatly reduce the seismic response, and is an effective means to improve the seismic safety of the structure. Considering the structural characteristics of the project, the improvement of the economy and the quality of the building, the use of story isolation technique in the enlarged base multiple tower-layer structure in the high-intensity region is an optimal scheme. Finally, several key technical issues such as the combined seismic isolation scheme of the enlarged base story isolation technique and the additional bending moment of the isolator and the tensile device of the isolator were discussed, which can provide some references for similar engineering practices.

\section{Introduction}

Seismic isolation technology is a good solution for high-rise buildings in high-intensity areas, and different scholars have carried out a lot of research and engineering practice [1-3]. In high-rise isolation buildings with various shapes and functions, multitower isolation structure with enlarged base is a typical representative. In the aspect of theoretical research on a large base-isolated structure, Domenico et al. [4] studied that the flag-shaped hysteretic behavior of shape memory alloys (SMAs) can be conveniently used for developing efficient isolation systems, providing energy dissipation without implying residual displacements. Barrera-Vargas et al. [5] studied a common solution for isolating civil engineering structures underground movements. Cesare et al. [6] studied the effects of the overstroke displacement of DCCSS and of displacement restrainers on the seismic response of base-isolated buildings considering a case study. Ferraioli and Mandara shows that [7] base isolation proved to be the more appropriate, also for the possibility offered by the geometry of the building to easily create an isolation interface at the ground level. Matsagar and Jangid [8] studied the retrofitting of various important structures using seismic isolation technique by incorporation of the layers of isolators at suitable locations. Zhao et al. [9] discussed the seismic performance of multitower base isolation structure. Deng et al. [10] studied the optimization of base isolation layer stiffness and yield force according to the characteristics of enlarged base and multitower; in the aspect of experimental research, Li [11] carried out the shaking table test on the large base single tower isolation structure model. All the above results showed that the isolation effect of the base isolation structure with enlarged base is good. 
At present, there are some challenges in adopting the base isolation scheme for multitower structure with enlarged base, such as uninterrupted function requirement of vertical elevator shaft and coordination and unification of structure for bottom commercial and upper residential structure. At the same time, the isolation layer at the bottom also makes the overall cost of the structure relatively high. Therefore, more in-depth study should be carried out on the location of the isolation layer of the enlarged base structure, so as to obtain a good structural scheme of the coordination and unification of the building use function and the seismic performance of the structure. The seismic response research and engineering design of the multitower story isolation structure with large base are carried out by Okada [12], Zhang [13], and Sun [14]. The results show that the interlayer isolation structure not only has a good isolation effect but also meets the requirements of building function as far as possible. According to the requirement of coordination and unification of building function and seismic performance of large base story isolation structure in the high-intensity area [15], this study takes a high-rise building with enlarged base and multitower in the high-intensity area as an example to study its seismic response and seismic performance and design and discuss some key technical problems, which can provide reference for similar engineering practice.

\section{Structural Scheme Selection of Enlarged Base and Multitower in the High-Intensity Area}

2.1. Project Overview. The construction area of the project is about $104,858 \mathrm{~m}^{2}$, including apartment, commercial, and basement. There are 2 floors underground for garage and 28 floors above ground. Among them, 1-3 floors are commercial supporting podiums and 4-28 floors are two apartment towers. The general plan and effect drawing of the building are shown in Figure 1. The roof height of the two towers is $93.8 \mathrm{~m}$, and the podium height is $15.4 \mathrm{~m}$. The plane of the podium is rectangular, and the plane size is about $103.2 \mathrm{~m} \times 82.3 \mathrm{~m}$; the plane $\mathrm{B}$ of the tower is L-shaped, and the plane a of the tower is T-shaped, which are relatively arranged on the east and west sides of the podium plane. As shown in Figure 2, the L-shaped plane long limb of tower B is retracted once at the elevation of $81.6 \mathrm{~m}$, and the T-shaped plane long limb of tower $\mathrm{A}$ is retreated twice at the elevation of 29.75 and $75.1 \mathrm{~m}$. The seismic fortification intensity of the project site is 8 degrees $(0.2 \mathrm{~g})$, and the characteristic period $T_{g}$ of the site is $0.4 \mathrm{~s}$.

2.2. Structural Features. The reinforced concrete frame core tube structure system is adopted for each tower, and reinforced concrete frame is adopted for podium with large chassis; the main structural characteristics of the core tube (shear wall) structure are as follows: (1) the upper two towers $\mathrm{B}$ and $\mathrm{A}$ are, respectively, L-shaped and T-shaped planes, which belong to the structural torsional irregularity; (2) the height direction is gradually retracted, tower B is retracted once, tower A is twice retracted, and the sudden change of tower mass and stiffness is large; and (3) the project is located in the strong earthquake area of 8 degrees, and the sudden change of the mass and stiffness of the tower will bring adverse effects on the overall structure.

In order to solve the disharmony of building function and the adverse effect of structural stress caused by the above structural characteristics, it is necessary to comprehensively consider the selection of structural scheme from two aspects of building use and seismic performance [14].

2.3. Structural Scheme Selection. According to the structural characteristics of the project, three technical schemes are selected in the initial stage, which are the traditional seismic scheme, the first floor base isolation scheme, and the interlayer isolation scheme.

2.3.1. Traditional Seismic Scheme. The irregularity of the structure brings many adverse seismic problems, and the high-intensity earthquake makes the interstory displacement angle and torsional displacement ratio of the whole structure difficult to meet the requirements of the code. It is necessary to divide the structure into five regular units and set five seismic joints on the corresponding plane (Figure 3 ). The scheme is technically feasible, but there are the following disadvantages: (1) the number of five seismic joints is large, which affects the use of the building; (2) the number of shear walls is large, and the section of frame column is large; and (3) the section of frame beam is large, which affects the indoor layout. The above factors lead to the low use quality of the building, and the "hard resistance" mode makes the structural economy relatively poor; it is necessary to obtain the technical scheme with economic and good seismic performance through other paths.

2.3.2. Base Isolation Scheme of the First Floor. The isolation layer is set on the basement roof, and the podium and tower above the ground are isolated as a whole to form the first floor bottom base isolation scheme (Figure 4). The main advantages of this scheme are as follows: it can greatly reduce the seismic response of tower and podium, the concept and principle of isolation are clear, and the details of isolation structure are easy to handle, which is conducive to improving the structure layout and improving the building quality [16]. However, the whole chassis including the podium needs to be equipped with isolation bearings under each transfer column, resulting in a large number of isolation bearings, and a total of 148 isolation bearings need to be arranged, which has an impact on the economy of the scheme.

2.3.3. Story Isolation Scheme. The isolation layer is set between the podium roof and the upper tower to form the interlayer isolation scheme (Figure 5). The main advantages of the scheme are as follows: it can greatly reduce the seismic response of the tower and podium, and it is helpful to improve the structure layout and the building quality. In addition, as the isolation bearings are only needed to be arranged under the transfer column at the bottom of the 


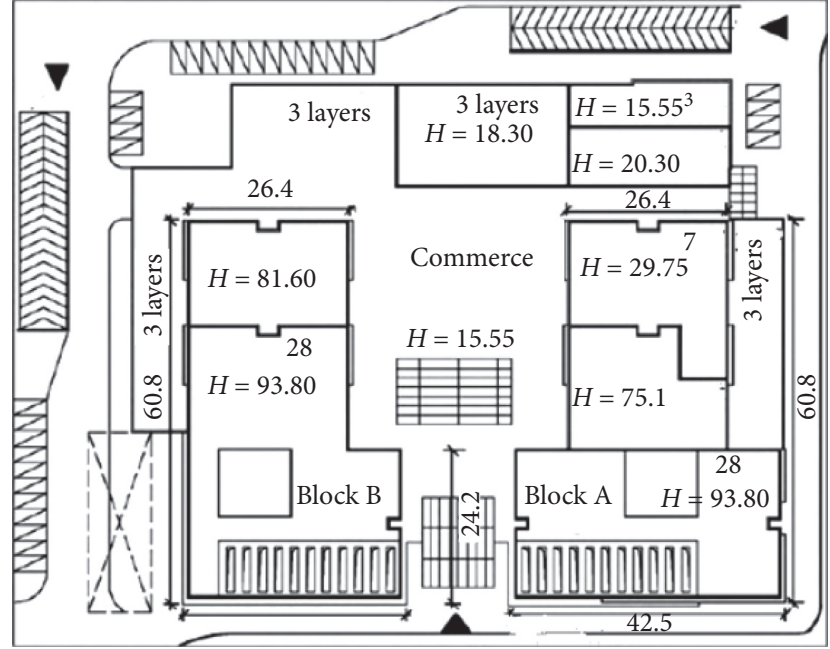

(a)

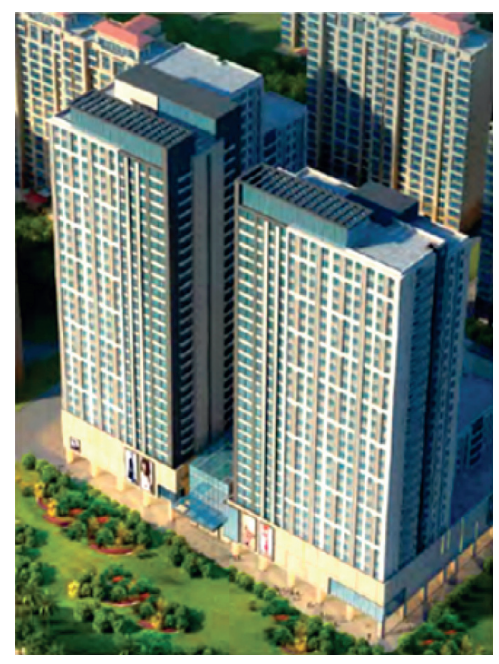

(b)

FIGURE 1: General plan and the architectural effect drawing of an enlarged base multitower high-rise building. (a) General plan of building/m. (b) Architectural renderings.

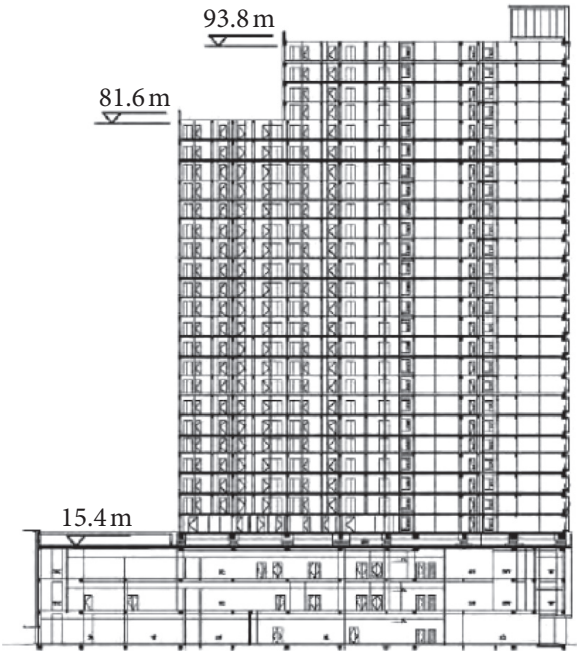

FIgURE 2: Schematic architectural section of tower B.

tower, 102 bearings are arranged in total, which makes the scheme more economical.

The calculation results of the above three technical schemes can meet the requirements of seismic performance of the structure. Considering the structural characteristics, economic efficiency, and building quality improvement of the project, the interlayer isolation scheme is finally selected as the implementation scheme. After adopting the interlayer isolation scheme, five seismic joints of the original seismic structure are cancelled, some of the tower shear walls are cancelled, the section of the tower frame column, and frame beam is optimized (Table 1), and the seismic response of the tower is greatly reduced, which is conducive to improving the structural layout (Figure 6) and improving the building quality.

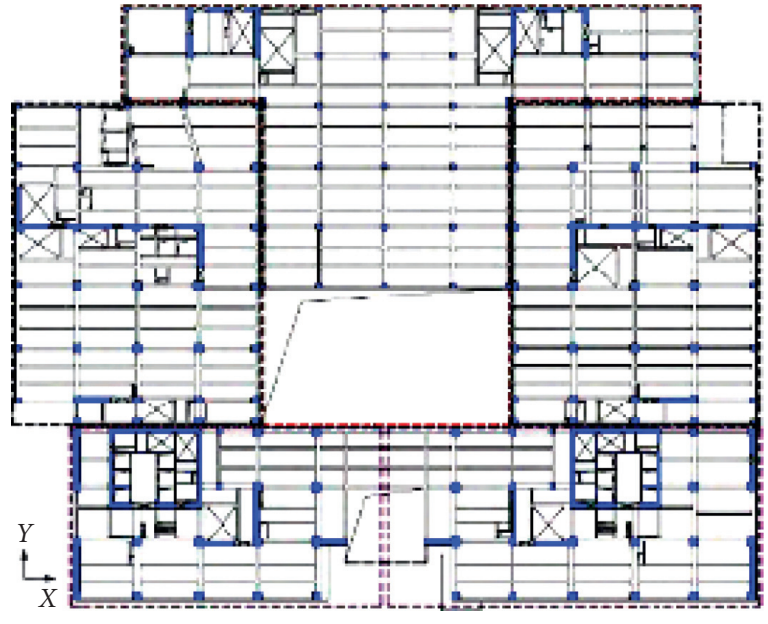

Figure 3: Joint drawing of the traditional seismic scheme.

\section{Structural Arrangement of the Isolation Layer}

3.1. Staggered Interlayer Isolation System. In order to avoid the elevator track of the vertical elevator shaft from hindering the horizontal deformation of the isolation layer, the isolation bearings are set at different elevations, the isolation bearings beyond the scope of the core tube of the tower are set on the top of the skirt, the shear wall of the core tube of the tower falls directly on the basement base, and part of the isolation bearings are set at the bottom of the core tube to form a staggered interlayer isolation structure system, as shown in Figure 7.

3.2. Combined Isolation Scheme. Due to the high structural height of the project, the structural period before isolation is long. In order to effectively extend the structural period and improve the isolation effect, the elastic sliding plate bearing with large vertical bearing capacity, small horizontal 


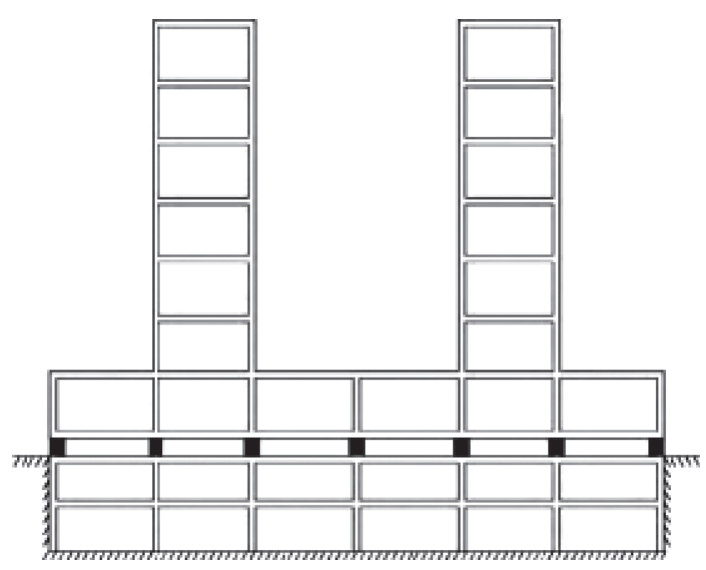

FIGURE 4: Base isolation diagram of the first floor.

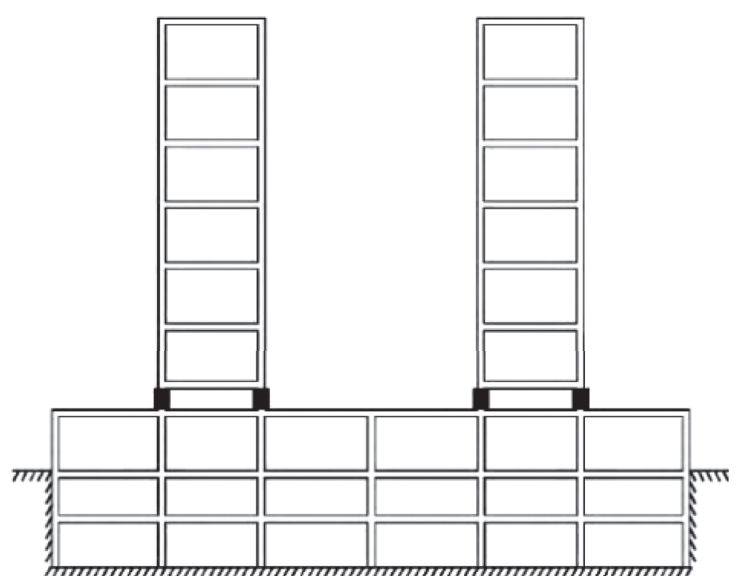

FIgURE 5: Schematic diagram of interlayer isolation.

TABLe 1: Optimization of main section of frame column and beam of the tower.

\begin{tabular}{lcc}
\hline Cross section comparison & Traditional seismic scheme & Story isolation scheme \\
\hline \multirow{2}{*}{ Frame beam } & $500 \times 600$ & $200 \times 1050($ reverse beam) \\
& $400 \times 700$ & $250 \times 600$ \\
\hline \multirow{2}{*}{ Frame column } & $1000 \times 1000$ & $900 \times 900$ \\
& $1200 \times 1200$ & $1000 \times 1000$ \\
\hline
\end{tabular}

stiffness, and strong energy dissipation capacity is adopted under some transfer columns, which is arranged in parallel with lead rubber bearing and natural rubber bearing to form a combined isolation scheme, so as to further reduce the stiffness of the isolation layer and increase the energy consumption of the isolation layer, which can reduce the seismic response more effectively.

3.3. Tensile Device. Due to the staggered height difference between the top isolation layer of skirt building and the bottom isolation layer of core tube, during the horizontal movement of the isolation layer, the rubber bearing at the bottom of the core tube connecting the two isolation layers is subjected to tensile stress due to rigid body rotation.
Therefore, a tensile device is set at the bottom of the core tube as the second protective line. Figure 8 shows the plane $360^{\circ}$ sliding tensile device developed in this project, which ensures that the tensile device can work normally when the isolation layer deforms at any angle $(\alpha)$ in the plane.

The working principle of the tension device used in this project is mainly reflected as follows: the upper steel frame is connected with the upper structure, the lower steel frame is connected with the foundation, and the sliding device with the rolling effect is set between the upper and lower steel frames. The tensile device has strong tensile capacity and large sliding deformation capacity, and the rolling friction force is small, which will not hinder the horizontal movement of the tension device in any direction. The tensile device was designed, and the mechanical property test was 


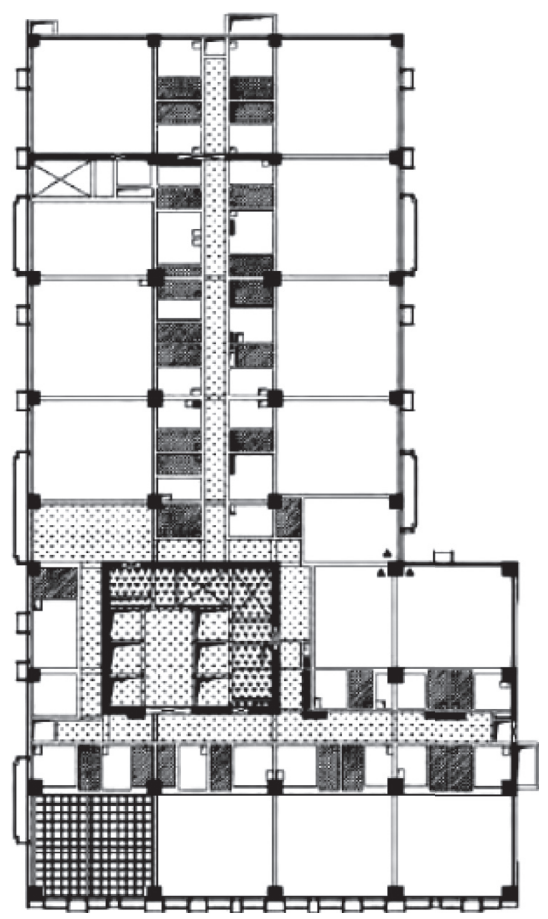

(a)

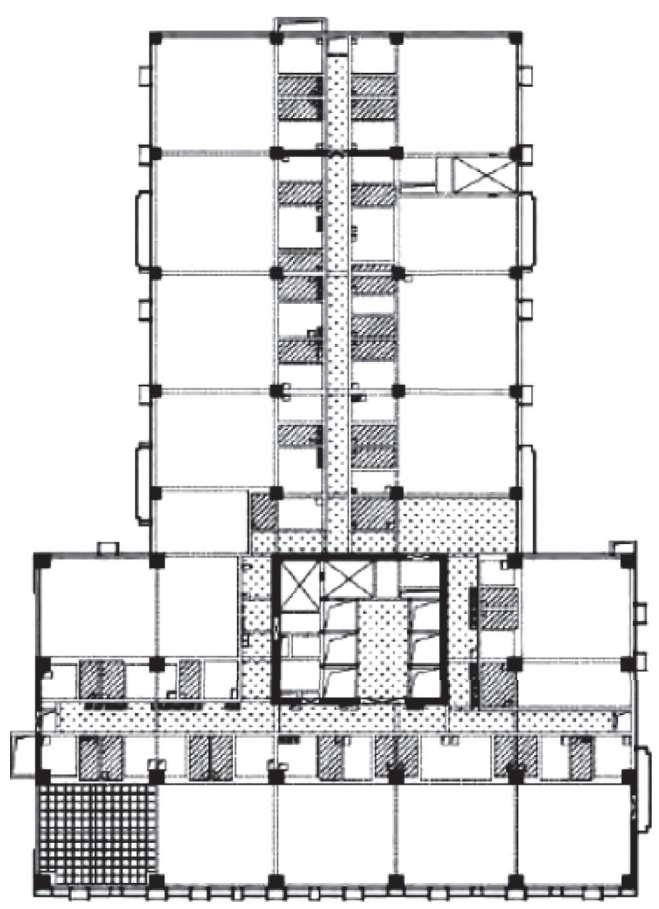

(b)

FIgure 6: Optimal layout of standard floor structure of the tower above isolation floor. (a) Tower B. (b) Tower A.

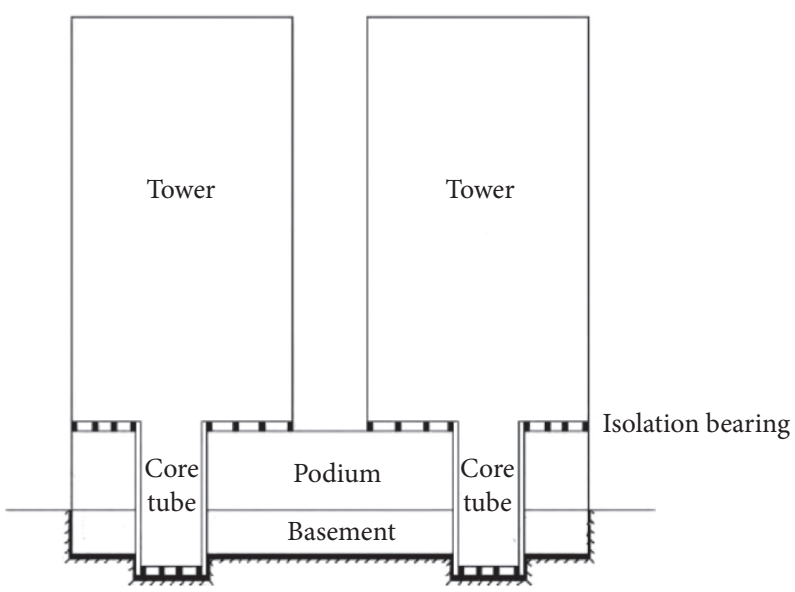

FIGURE 7: Schematic diagram of the staggered story isolation structure system.

completed, as shown in Figure 9. The test results show that the tensile strength of the device is strong, the sliding friction force is small, and the sliding deformation capacity is large.

3.4. Isolation Layer Design. In order to obtain reasonable arrangement of isolation bearings and a good isolation effect, the combined isolation scheme is adopted in the project, in which there are 102 isolation bearings of three types: lead rubber bearing (LRB), natural rubber bearing (LNR), and elastic sliding plate bearing (ESB); there are five kinds of rubber bearings with diameters ranging $900-1300 \mathrm{~mm}$, and the diameter of rubber bearings of elastic slide bearings is $1300 \mathrm{~mm}$. The horizontal restoring force of the isolation layer, the eccentricity of the isolation layer, and the earthquake reduction coefficient are taken as the control objectives for the arrangement of the isolation bearings. The final plane layout of the isolation bearings is shown in Figure 10, in which the supports in the dotted frame of the two towers are arranged at the bottom of the core tube, and the rest are arranged on the roof of the skirt; the eccentricity of the isolation layer is less than $1.5 \%$, the equivalent damping ratio is $26.5 \%$, and combined with many factors such as base shear force, acceleration, interlayer displacement, and support displacement, the effective stiffness is $2420 \mathrm{KN} / \mathrm{mm}$.

The horizontal restoring force characteristics of the isolation layer are determined by the lead core, rubber, and elastic sliding plate bearing. The horizontal restoring force 


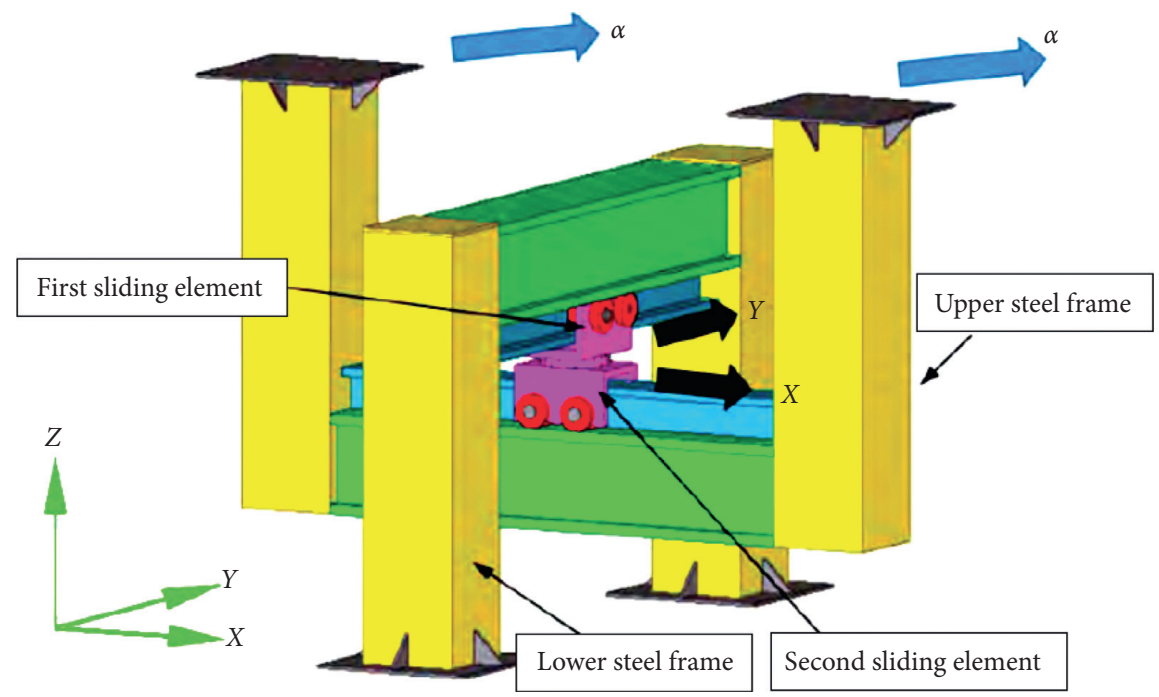

Figure 8: Structural diagram of the tensile device ( $\alpha$ is any angle in XY plane).
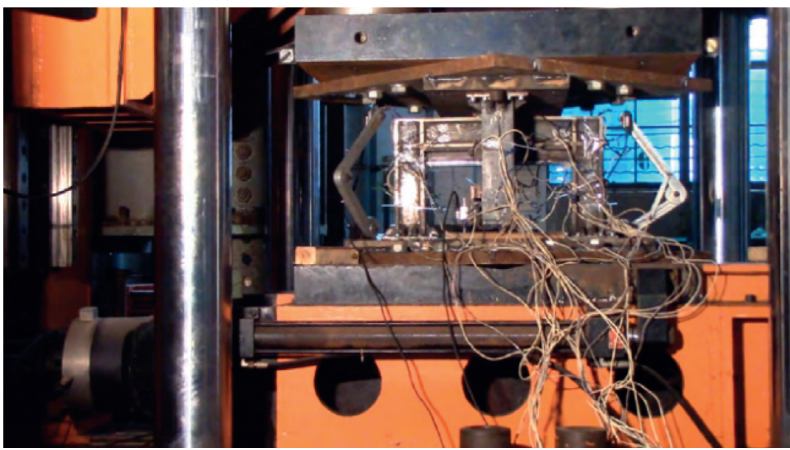

Figure 9: Mechanical property test of the tensile device.

characteristics of the isolation layer of the project are shown in Figure 11. It can be seen from Figure 10 that the yield stress of the isolation layer is greater than the horizontal shear force under the action of wind load, and the structure meets the wind resistance performance goal.

\section{Seismic Response Analysis of Isolated Structures}

4.1. Structural Analysis Model. In order to study the seismic response of multitower story isolation structure with large chassis, the finite element analysis was carried out by ETABS software; the earthquake intensity is 8 , the damping ratio of structure is 0.05 , the peak value of seismic acceleration is $0.2 \mathrm{~g}$, and the characteristic period is $0.4 \mathrm{~s}$; the duration and proportion of seismic wave are automatically set by ETABS. The calculation model is based on the assumption that the isolation bearing is locally nonlinear and the rest of the structural members are elastic. Since the vertical tensile and compressive stiffness of rubber isolator element is equal and the isolation rubber bearing has the characteristics of different vertical tension and compression stiffness, the combination of rubber isolator element and gap element is used to simulate its vertical stiffness mechanical constitutive model in ETABS, and the tensile stiffness is taken as $1 / 7$ of the compression stiffness; the elastic sliding plate bearing is simulated by friction isolator element. The Rize method [17] is used to analyze the dynamic characteristics of the structure, the FNA method [18] is used to analyze the dynamic time history, and the second-order effect of gravity load is considered in each analysis process.

When considering the nonlinear combination of the gravity load and seismic action, the nonlinear gravity load condition is adopted first, and then, the seismic action under different working conditions is applied under the action of maintaining the gravity load; the overall analysis model is shown in Figure 12. Because the bottom elevation of the core tube is lower than that of the second floor, the ETABS analysis model adds two model layers below the floor elevation of the second floor underground; there are 4 floors underground and 32 floors above the ground, and the total floor number of the model is 36 , in which the floor number in the calculation results is the model floor number.

4.2. Earthquake Reduction Coefficient. The comparison of the first two translational periods of the structure before and after the isolation is given in Table 2. It can be seen that the 


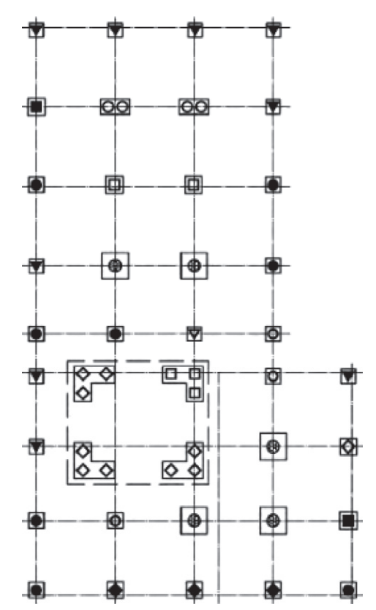

$\triangle$ Rubber LNR900

- Lead core LRB900

$\nabla$ Rubber LNR1000

$\nabla$ Lead core LRB1000

O Rubber LNR1100

- Lead core LRB1100

$\diamond$ Rubber LNR1200

- Lead core LRB1200

$\square$ Rubber LNR1300

Lead core LRB1300

† Sliding plate ESB1300

(a)

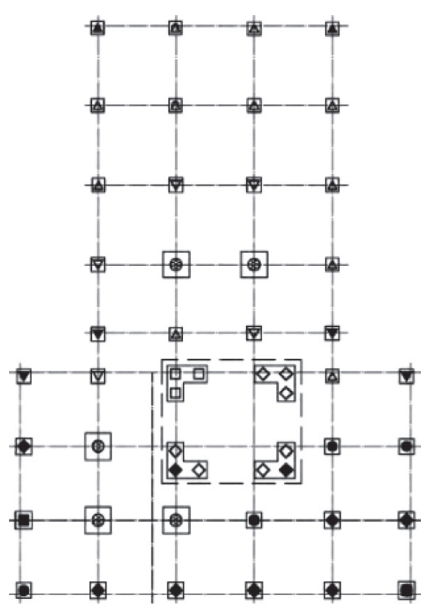

$\triangle$ Rubber LNR900

- Lead core LRB900

$\nabla$ Rubber LNR1000

$\nabla$ Lead core LRB1000

○ Rubber LNR1100

- Lead core LRB1100

$\diamond$ Rubber LNR1200

- Lead core LRB1200

$\square$ Rubber LNR1300

Lead core LRB1300

Sliding plate ESB1300

(b)

Figure 10: Arrangement of isolation bearing in the isolation layer. (a) Tower B. (b) Tower A.

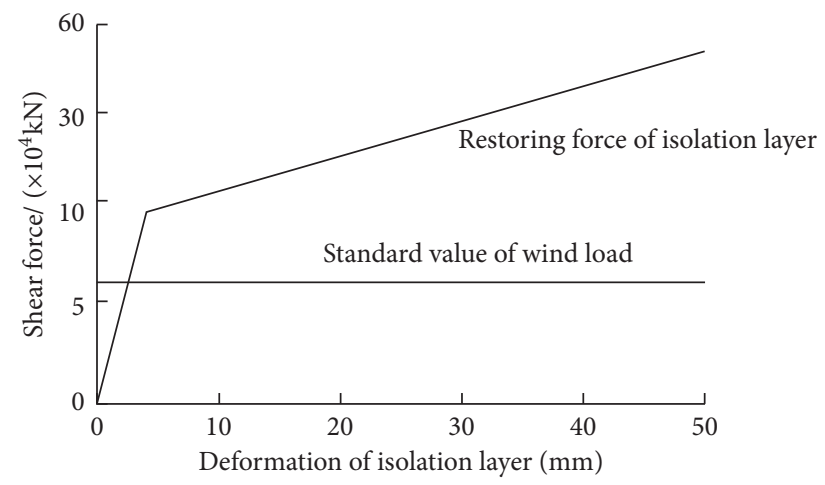

FIGURE 11: Horizontal restoring force characteristics of the isolation layer.

period of the isolated structure is obviously prolonged, which is conducive to reducing the seismic response of the structure.

In code for seismic design of buildings (GB 50011-2010) [19] (hereinafter referred to as the code for seismic design of buildings), the larger values of shear ratio and overturning moment ratio of all floors are used as the evaluation index of the seismic isolation effect of isolated buildings, that is, the earthquake reduction coefficient. Figures 13 and 14 show the earthquake reduction coefficient of tower $\mathrm{A}$ and tower $\mathrm{B}$, respectively. It can be seen that the maximum horizontal damping coefficient of tower $\mathrm{A}$ and tower $\mathrm{B}$ is 0.411 and 0.445 and that of podium is 0.560 , which indicates that the seismic response of the structure is significantly reduced and the isolation effect is good.

4.3. Story Drift Angle. The time history analysis of bidirectional horizontal seismic action is used to check the deformation of the structure under the action of earthquake, the analysis method meets the requirements of GB 50011-2010, accidental eccentricity (maximum displacement ratio of accidental eccentricity 1.13 in $X$ direction and 1.34 in $Y$ direction) and bidirectional seismic actions are considered in the mode response spectrum analysis, the average value of two groups of artificial waves and five 


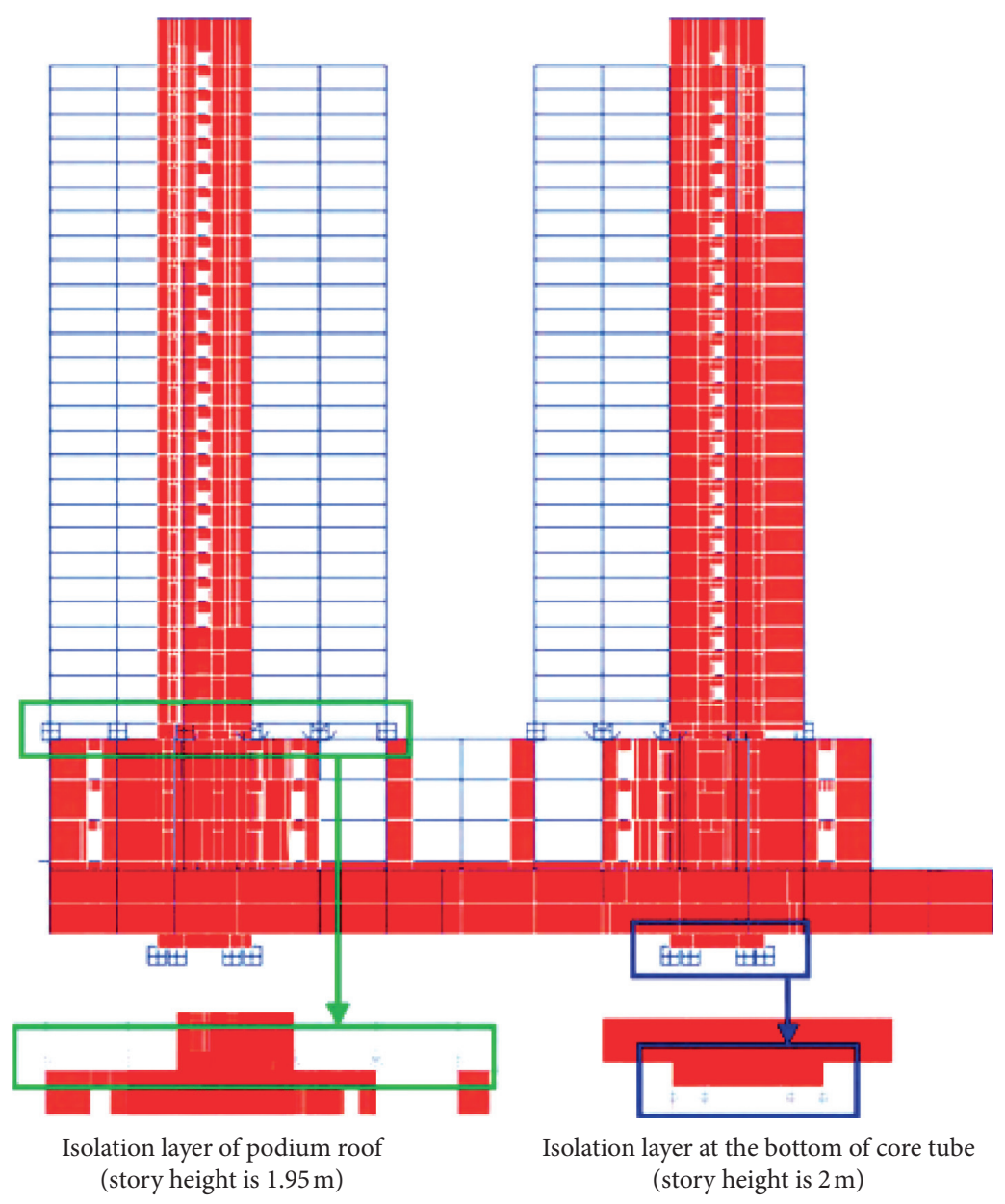

FIGURE 12: Integral analysis model of isolated structure.

TABLE 2: Comparison of the period of the structure before and after isolation.

\begin{tabular}{lcc}
\hline Period & Fundamental period in $X$ direction/s & Fundamental period in $Y$ direction/s \\
\hline Before isolation & 2.38 & 2.25 \\
After isolation & 4.77 & 4.69 \\
\hline
\end{tabular}

groups of natural waves are taken as the calculation results, in which the seismic waves are five groups of actual seismic natural waves (chi chi, Taiwan; Hector Mine; Kocaeli, Turkey; superstition hills; San Fernando) and two groups of artificial waves (USER2, USER3) [20], the time history analysis results show that the bottom shear force of each seismic wave is not less than $65 \%$ of the response spectrum method, and the average value of the calculated bottom shear force is not less than $80 \%$ of the response spectrum method. The calculation results of interstory displacement angle and floor displacement are shown in Figure 15 and Table 3. The maximum interstory displacement angle of the tower is $1 /$ 685 , the lateral displacement of the top floor of the tower is $226 \mathrm{~mm}$, and the deformation of the isolation layer is $149 \mathrm{~mm}$, which shows that the deformation of the structure after isolation mainly occurs in the isolation layer, and the deformation of the structure above the isolation layer is small, basically in elastic state, and the isolation effect is good. The maximum interstory displacement angle of the podium below the isolation layer is $1 / 1122$, and the lateral displacement of the top floor of the podium is $9.3 \mathrm{~mm}$, which indicates that the podium has sufficient stiffness.

4.4. Bearing Capacity and Deformation Checking Calculation of Isolation Bearing. The two-way horizontal and vertical seismic action time history analysis is used to check the bearing capacity of isolation bearing under rare earthquake, the average value of two groups of artificial waves and five groups of natural waves is taken as the calculation results, and the bearing capacity and deformation results of the isolation bearing are given in Table 4 .

According to the code, the vertical compressive stress and tensile stress of the isolation bearing should not be greater than $30 \mathrm{MPa}$ and $1 \mathrm{MPa}$, respectively. The maximum compressive stress of isolation bearing under three- 


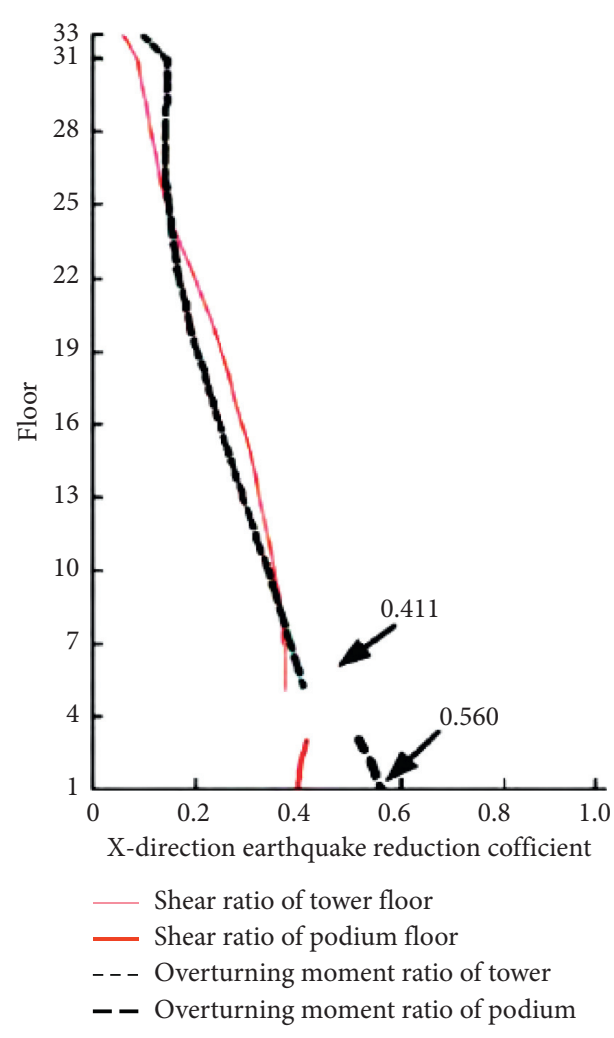

(a)

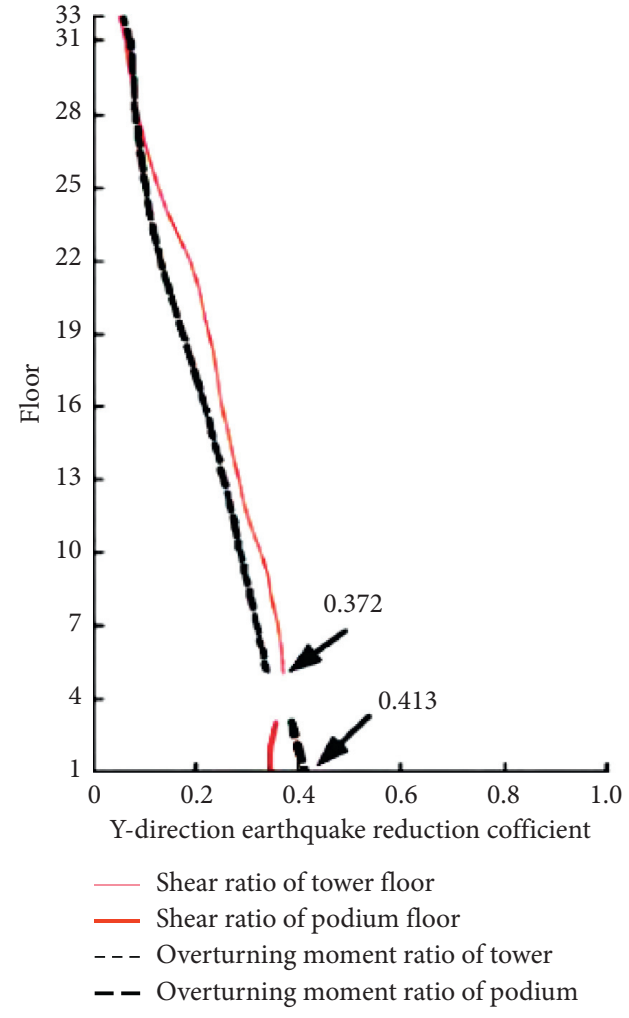

(b)

FIgURE 13: Horizontal earthquake reduction coefficient of tower A.

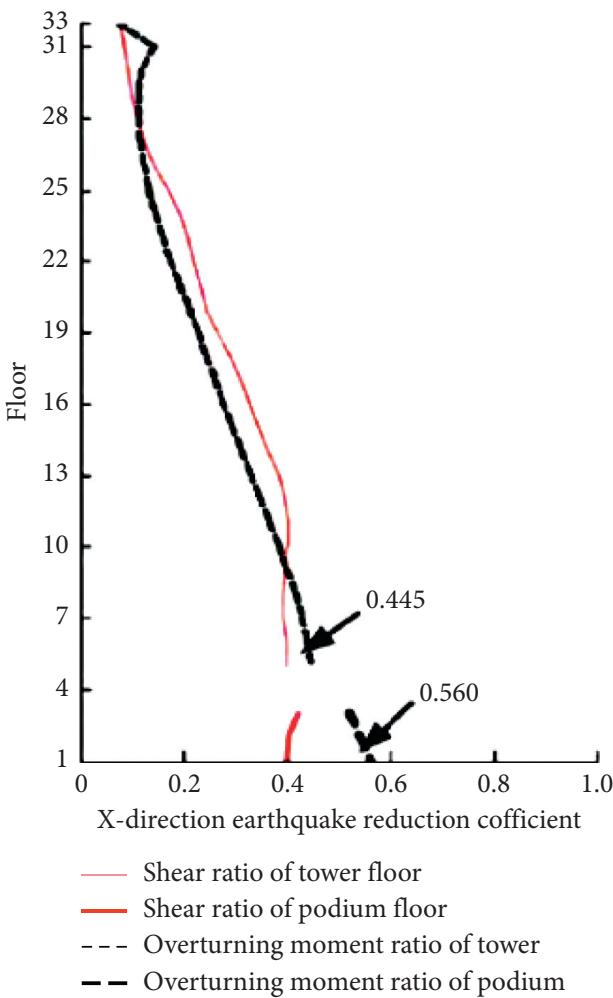

(a)

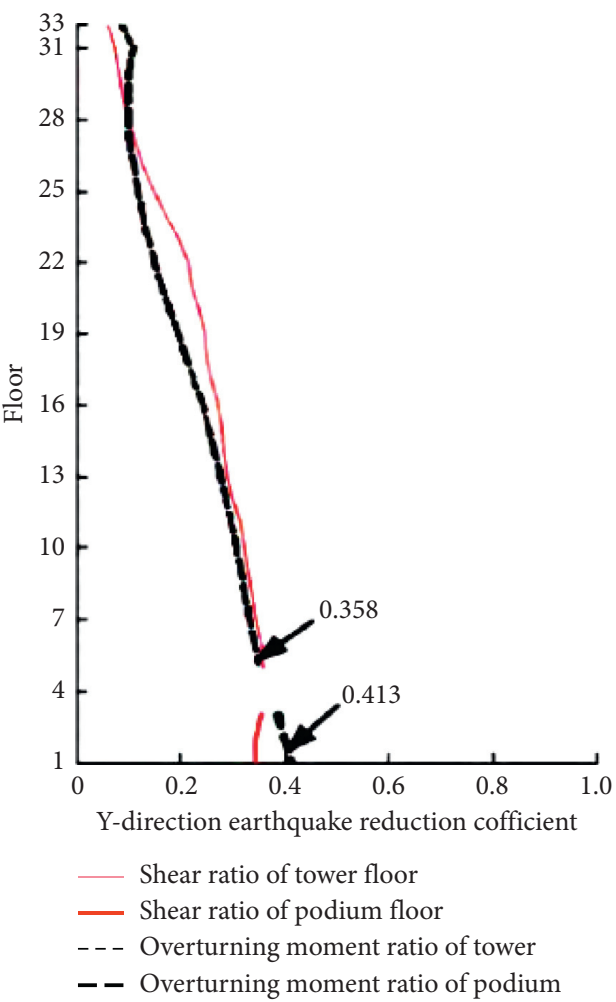

(b)

FIgURE 14: Horizontal earthquake reduction coefficient of tower B. 


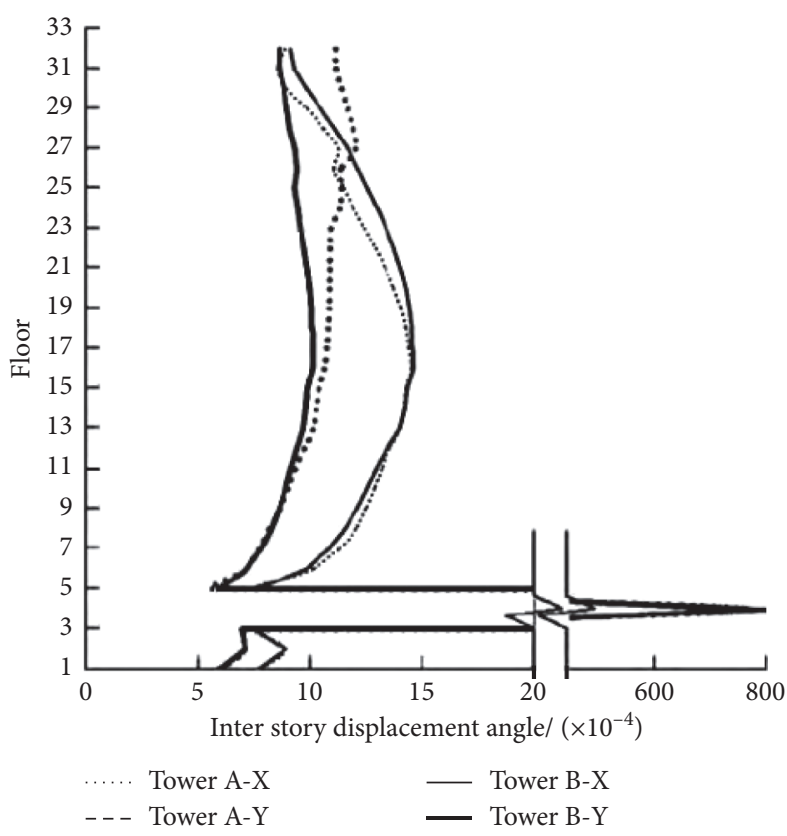

(a)

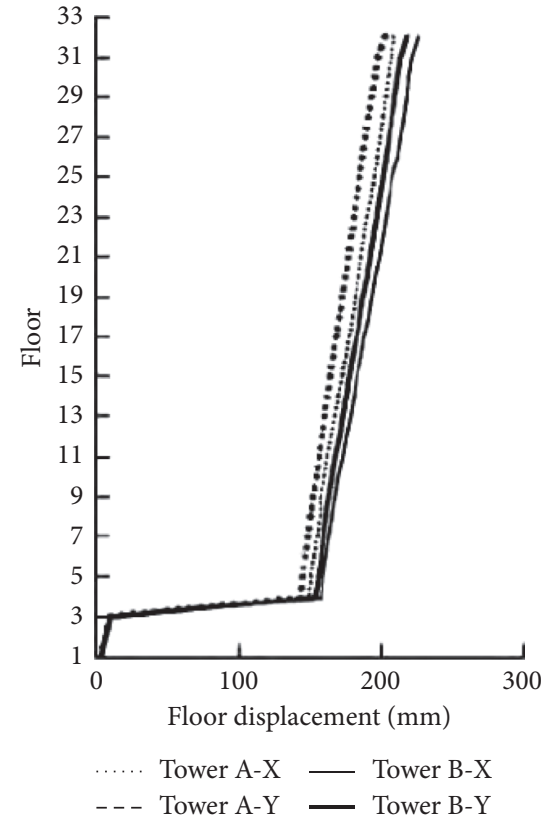

(b)

Figure 15: Interstory displacement angle and floor displacement curve under fortification earthquake.

TABLE 3: Interstory displacement angle of structure under fortification earthquake.

\begin{tabular}{lcc}
\hline Interstory displacement angle & $X$ direction & $Y$ direction \\
\hline Tower A & $1 / 690$ & $1 / 830$ \\
Tower B & $1 / 685$ & $1 / 991$ \\
Podium & $1 / 1122$ & $1 / 1408$ \\
\hline
\end{tabular}

TABLE 4: Isolation bearing pressure, tensile stress, and deformation.

\begin{tabular}{|c|c|c|c|}
\hline Location and type of support & Compressive stress/MPa & Tensile stress/MPa & Maximum deformation in vector direction $/ \mathrm{mm}$ \\
\hline Rubber bearing & 25.1 & 0.32 & 466 \\
\hline 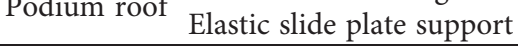 & 20.9 & 0.70 & 448 \\
\hline $\begin{array}{l}\text { Rubber bearing at the bottom of core } \\
\text { tube }\end{array}$ & 22.9 & 0 (compression) & 431 \\
\hline
\end{tabular}

dimensional earthquake is $25.1 \mathrm{Mpa}$, and the vertical compressive stress meets the requirements of the code. The maximum tensile stress of isolation bearing is $0.70 \mathrm{Mpa}$ under the action of three-dimensional earthquake, and the rubber bearing at the bottom of core tube is always under compression. There are 27 rubber bearings with tensile stress, and the proportion of tension bearing to the total number of supports is $26.5 \%$ (less than $30 \%$ ). In the whole process of time history analysis, the maximum number of supports with tensile stress at the same time is only 15 (only $14.7 \%$ of the total number of bearings), and the ratio of tensile bearing number and vertical tensile stress meets the requirements of the code.

It can be seen from Table 4 that the maximum deformation of isolation bearing in vector direction is $466 \mathrm{~mm}$, and the horizontal limit value of rubber bearing with diameter less than $900 \mathrm{~mm}$ is $495 \mathrm{~mm}$, which meets the requirements of the specification.

4.5. Mechanical Performance under Rare Earthquake. In this project, the dynamic elastoplastic time history analysis is carried out by using the high-performance nonlinear analysis software SAUSAGE [21]. The mechanical model of the isolation rubber bearing is simulated by the isolation bearing element with different vertical tension and compression stiffness, and the mechanical model of the elastic sliding plate bearing is modeled by the friction pendulum bearing element. According to the calculation [22], the maximum interstory displacement angle of tower and podium is given in Table 5, and the maximum interstory displacement angle of tower is $1 / 142$ and that of podium is $1 /$ 
TABLE 5: Interstory displacement angle of structure under rare earthquake.

\begin{tabular}{lccc}
\hline Interstory displacement angle & $X$ direction & $Y$ direction & Limits \\
\hline Tower A & $1 / 166$ & $1 / 172$ & $1 / 100$ \\
Tower B & $1 / 142$ & $1 / 181$ & $1 / 100$ \\
Podium & $1 / 221$ & $1 / 294$ & $1 / 200$ \\
\hline
\end{tabular}

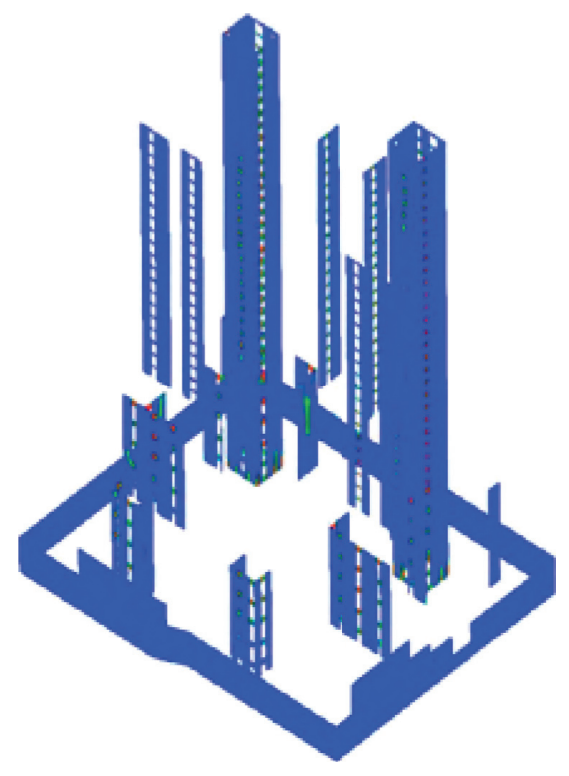

(a)

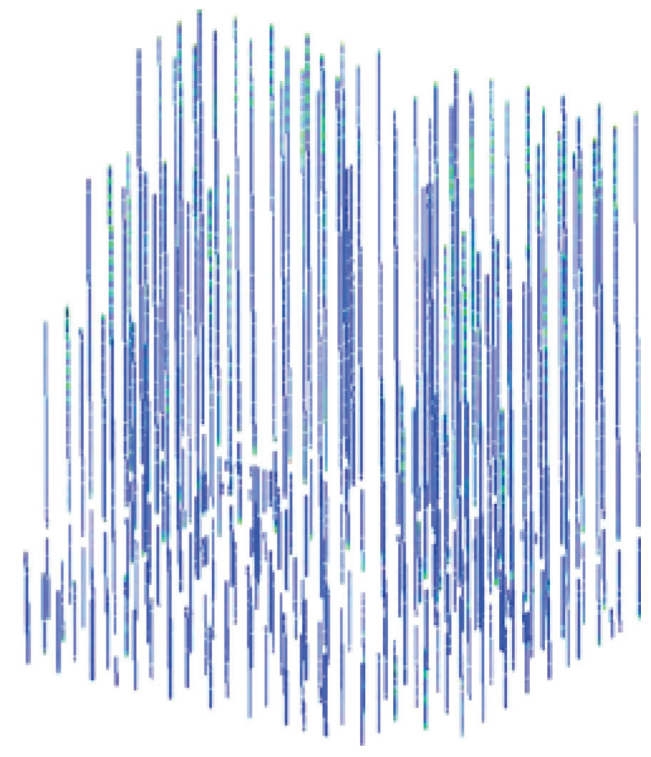

(b)

FIGURE 16: Damage of shear walls and frame columns under artificial wave $Y$ direction earthquake. (a) Overall damage of shear wall. (b) Damage of frame column.

221. All of them meet the requirements of the code for design of the middle story displacement angle, and the tower and podium have sufficient stiffness.

Figure 16 shows the damage of shear wall and frame column under the action of artificial wave $Y$ main direction, and the damage model for the shear walls and frame columns is the improved Park-Ang damage model [23]. After the tower adopts interlayer isolation technology, the structural response under large earthquake is relatively small, and the core tube is set with reasonable coupling beam to dissipate energy, and most of the shear walls and frame columns do not appear as obvious damage. Figure 17 shows the energy curve of the structure under the artificial wave $\mathrm{Y}$ main direction earthquake. It can be seen that the energy consumption of the isolation bearing accounts for about $50 \%$ of the total external force work, and the energy dissipation through the isolation layer can effectively reduce the seismic response of the upper structure on the isolation layer.

\subsection{Other Key Technical Issues}

4.6.1. Advantages of Combined Isolation Scheme. Elastic sliding plate bearing is an isolation bearing composed of rubber bearing part, sliding material (polytetrafluoroethylene plate), sliding panel (stainless steel plate), and upper and lower connecting steel plate (Figure 18); the friction pair composed of PTFE plate and stainless steel plate provides good friction energy consumption. Compared with the isolation rubber bearing, the elastic sliding plate bearing has the advantages of large vertical bearing capacity, small horizontal stiffness, large sliding displacement, and strong energy dissipation capacity. In addition, the elastic sliding plate support cannot bear the vertical tension and must be kept in the compression state. Therefore, the elastic sliding plate support should be arranged in the position where the internal axial force changes little and always keeps the compression state [24]. Table 6 provides the comparison results of different isolation schemes, compared with the traditional isolation scheme using lead rubber bearing and natural rubber bearing, the combined isolation scheme formed by parallel connection of lead rubber bearing, natural rubber bearing, and elastic sliding plate bearing that can prolong the isolation period of the structure by $6 \%$, reduce the seismic force by $8 \%$, and obtain a better isolation effect.

4.6.2. Reasonable Consideration of Additional Bending Moment of Isolation Bearing. Due to the large deformation of the isolation bearing, the additional bending moment of the isolation bearing and the eccentric bending moment formed by the gravity load of the upper structure constitute the additional bending moment of the isolation bearing 


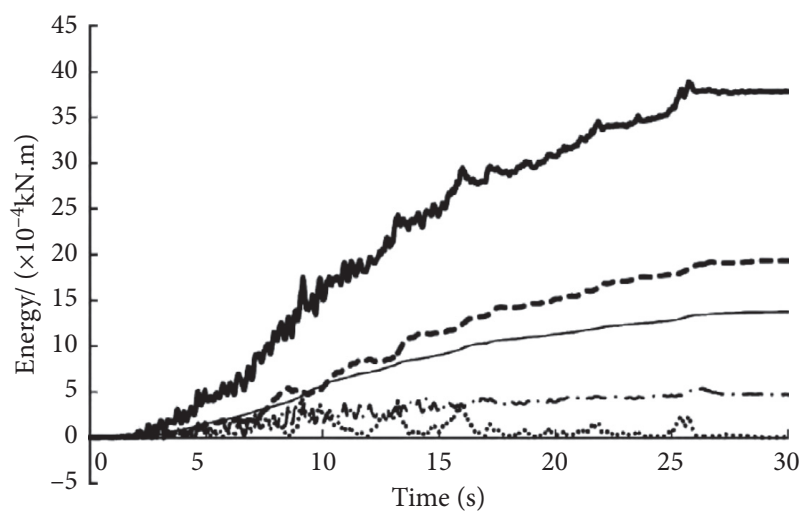

- - - Energy consumption of isolation bearing

_ Modal damping energy consumption

...- Strain energy

...... Kinetic energy

— External work

Figure 17: Energy curve of structure under artificial wave Y main direction earthquake action.

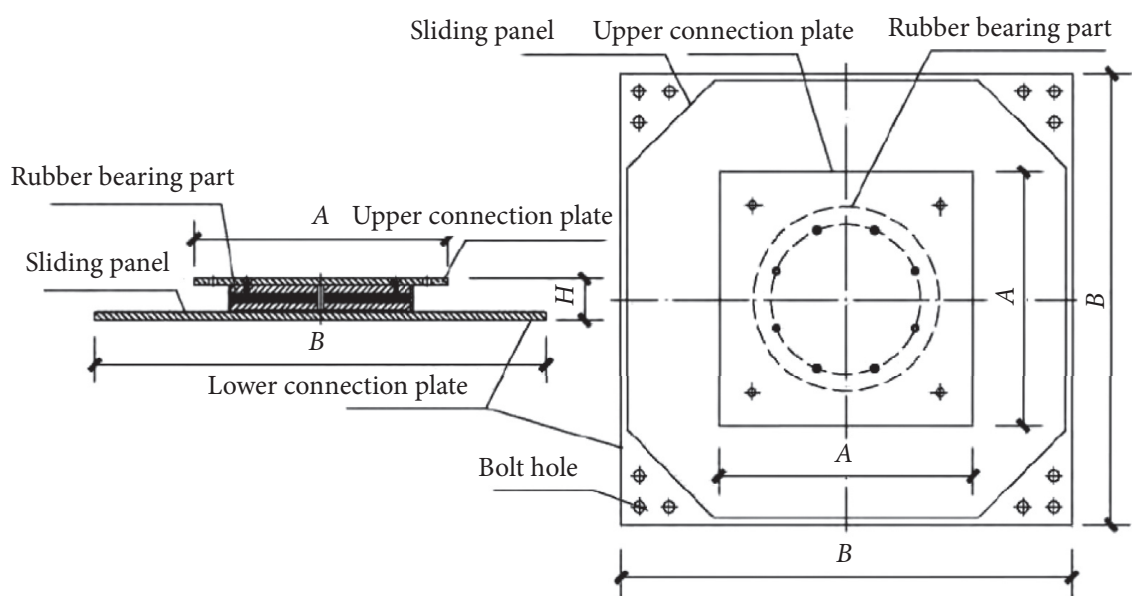

Figure 18: Structural diagram of elastic sliding plate support.

TABle 6: Comparison of different isolation schemes.

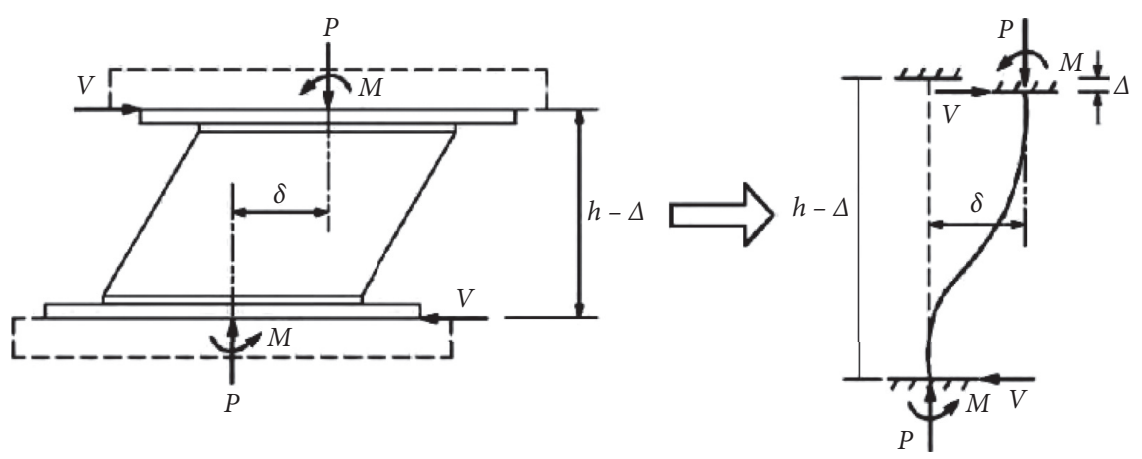

FIGURE 19: Calculation diagram of additional bending moment of isolation bearing. 
(Figure 19). The additional bending moment influence of the isolation bearing should be considered for the vertical members directly supporting the isolation layer below the isolation layer. In the design, attention should be paid to whether the software program has reflected the influence of the additional eccentric moment of the isolation bearing on the internal force of the substructure. In the engineering design, the maximum bearing reaction (axial force, shear force, and additional bending moment) of the isolation bearing can be directly input into the model [25], in order to ensure that the relevant components meet the bearing capacity requirements under large earthquakes.

\section{Conclusion}

In this study, the story isolation technology is applied to a high-rise building with enlarged base and multitower in the high-intensity area. The isolation layer is designed, the seismic response of the whole structure is analyzed, and the following conclusions are obtained:

(1) In the high-rise building structure with enlarged base and multitower in the high-intensity area, the application of isolation technology can greatly reduce the seismic response, which is an effective means to improve the seismic safety of the structure

(2) Considering the structural characteristics, economy, and building quality of the project, it is a preferred implementation scheme to adopt the interlayer isolation technology in the multitower structure with enlarged base in the high-intensity area

(3) The eccentricity and earthquake reduction coefficient of the isolated structure are reasonable, and the overall earthquake reduction effect is good. The bearing capacity, deformation, and elastic-plastic deformation of the structure meet the requirements of the code under rare earthquake, which further verifies that the application of interlayer isolation technology in the high-intensity area is safe and feasible.

(4) The design and discussion of the combined isolation scheme, the additional bending moment of the isolation bearing, and the bearing tension device are carried out, which can provide reference for similar engineering practice

\section{Data Availability}

The data used to support the findings of this study are available from the corresponding author upon request.

\section{Conflicts of Interest}

The authors declare that they have no conflicts of interest.

\section{Acknowledgments}

This work was supported by the National Natural Science Foundation of China (50978168) and Changchun Science and Technology Support Plan Project (2017zyg29).

\section{References}

[1] W. F. He, Y. S. Huang, W. G. Liu et al., "Uplift sway coupled dynamic model and seismic response analysis of high-rise isolated structures," Journal of Building Structures, vol. 40, no. 12, pp. 11-20, 2019.

[2] J. Okada and C. Yoshida, "Structural design of zhongzhidao music tower," Building Structure, vol. 45, no. 11, pp. 43-50, 2015.

[3] S. Sanaye and A. Sarrafi, "Cleaner production of combined cooling, heating, power and water for isolated buildings with an innovative hybrid (solar, wind and LPG fuel) system," Journal of Cleaner Production, vol. 279, pp. 222-226, 2020.

[4] D. D. Domenico, E. Gandelli, and V. Quaglini, "Adaptive isolation system combining low-friction sliding pendulum bearings and SMA-based gap dampers," Engineering Structures, vol. 212, pp. 110536-110542, 2020.

[5] C. A. Barrera-Vargas, I. M. Díaz, J. M. Soria, and J. H. GarcíaPalacios, "Enhancing friction pendulum isolation systems using passive and semi-active dampers," Applied Sciences, vol. 10, no. 16, pp. 5621-5629, 2020.

[6] A. D. Cesare, F. C. Ponzo, and A. Telesca, "Improving the earthquake resilience of isolated buildings with double concave curved surface sliders," . Engineering Structures, vol. 228, pp. 111498-111504, 2020.

[7] M. Ferraioli and A. Mandara, "Base isolation for seismic retrofitting of a multiple building structure: design, construction, and assessment," Mathematical Problems in Engineering, vol. 2017, pp. 1-24, 2017.

[8] V. A. Matsagar and R. S. Jangid, "Base isolation for seismic retrofitting of structures," Practice Periodical on Structural Design and Construction, vol. 13, no. 4, pp. 175-185, 2008.

[9] N. Zhao, K. Ma, T. Li et al., "Seismic response of high-rise isolation structure with large base plate and multi tower," China Civil Engineering Journal, vol. 43, no. S1, pp. 255-258, 2010.

[10] Z. Deng, L. W. Ye, Y. Q. Yu et al., "Design of multi tower isolation structure with enlarged base," Building Structure, vol. 45 , no. 8, pp. 13-18, 2015.

[11] C. K. Li, Shaking Table Test of Single Tower Isolation Structure with Large chassis, Fuzhou University, Fuzhou, China, 2016.

[12] Z. T. Zhang, C. C. Xia, R. Fan et al., "Story isolation design of Suqian suhao Ginza," Building Structure, vol. 43, no. 19, pp. 54-59, 2013.

[13] Z. Sun, W. Q. Liu, S. G. Wang et al., "Design and seismic response analysis of interlayer isolation structure of sohao Ginza," Building Structure, vol. 43, no. 18, pp. 58-63, 2013.

[14] China Construction Industry Press, Code for Seismic Design of Buildings: GB 50011-2010, p. 66, China Construction Industry Press, Beijing, China, 2010.

[15] Q. J. Luo, Y. Tan, M. X. Guo et al., "Seismic isolation structure design of $100 \mathrm{~m}$ high residential building in Kunming Tianhu Jingxiu shed renovation project," Building Structure, vol. 46, no. 11, pp. 33-38, 2016.

[16] L. L. Xie, C. T. Yang, A. Q. Li et al., "Experimental investigation of the seismic performance of flexible pipes for 
seismically isolated buildings," Engineering Structures, vol. 222, pp. 132-137, 2020.

[17] E. L. Wilson, "Dynamic analysis by direct superposition of Ritz vectors," Earthquake Engineering \& Structural Dynamics, vol. 10, no. 6, pp. 813-821, 2010.

[18] X. N. Wang, G. Zhao, J. Zhong et al., "Elastic-plastic analysis and research of large profiled structure under rare strong earthquakes based on FNA method," Advanced Materials Research, vol. 838-841, pp. 1556-1561, 2014.

[19] E. Gandelli and V. Quaglini, "Effect of the static coefficient of friction of curved surface sliders on the response of an isolated building," Journal of Earthquake Engineering, vol. 24, no. 9, pp. 1361-1389, 2018.

[20] R. K. Lu, Isolation Design and Seismic Response Analysis of Single Tower Structure with Large Base Plate, Xi'an University of science and technology, Xi'an, China, 2018.

[21] B. J. Qiao, Z. S. Li, C. M. Liu et al., "Application of open GL graphics rendering technology in the nonlinear analysis software of PKPM-SAUSAGE," Civil Engineering Information Technology, vol. 7, no. 5, pp. 13-18, 2015.

[22] R. Laguardia, C. Morrone, M. Faggella, and R. Gigliotti, "A simplified method to predict torsional effects on asymmetric seismic isolated buildings under bi-directional earthquake components," Bulletin of Earthquake Engineering, vol. 17, no. 11, pp. 6331-6356, 2019.

[23] R. Rajabi, M. Barghi, and R. Rajabi, "Investigation of ParkAng damage index model for flexural behavior of reinforced concrete columns," The Structural Design of Tall and Special Buildings, vol. 22, no. 17, pp. 1350-1358, 2013.

[24] M. Patricia, "Dynamic analysis of a base isolated building having zener rheological connections at seismic unidirectional translations," Applied Mechanics and Materials, vol. 4208, no. 801, pp. 171-175, 2015.

[25] A. Calabrese, M. Spizzuoco, S. Strano, and M. Terzo, "Hysteresis models for response history analyses of recycled rubber-fiber reinforced bearings (RR-FRBs) base isolated buildings," Engineering Structures, vol. 178, no. 1, pp. 635-644, 2019. 